\title{
Processing complex graphemes in handwriting production
}

\author{
Sonia KandeL \\ Laboratoire de Psychologie et NeuroCognition, CNRS UMR 5105 \\ Université Pierre Mendès France, Grenoble, France \\ GIPSA-Lab, CNRS UMR 5216, Grenoble, France \\ and Institut Universitaire de France, Paris, France \\ AND \\ Elsa SPINelli \\ Laboratoire de Psychologie et NeuroCognition, CNRS UMR 5105 \\ Université Pierre Mendès France, Grenoble, France \\ and Institut Universitaire de France, Paris, France
}

\begin{abstract}
Recent studies on handwriting production and neuropsychological data have suggested that orthographic representations are multilevel structures that encode information on letter identity and order, but also on intermediate-grained processing units such as syllables and morphemes. This study on handwriting production examined whether orthographic representations also include a graphemic-processing level. French adults wrote words containing an embedded one-, two-, or three-letter grapheme (e.g., A in CLAVIER, AI in PRAIRIE, AIN in PLAINTE) on a digitizer. The results for letter duration revealed that the timing of movement processing depends on grapheme length (e.g., the duration of A for one-letter graphemes was shorter than that for two-letter graphemes, which, in turn, was shorter than that for three-letter graphemes). Two- and three-letter graphemes start to be processed before we start to write them. The results therefore revealed that orthographic representations also encode information on grapheme complexity.
\end{abstract}

Many studies of handwriting production implicitly or explicitly assume that writing a word consists merely of producing one letter after the other. For this reason, Van Galen's (1991) model of handwriting production postulated that we memorize and recall the spelling of words as abstract linear sequences that exclusively encode information on letter identity and order. The handwriting system would activate the orthographic representations of words such as set and sea as $\mathrm{S}_{1} \mathrm{E}_{2} \mathrm{~T}_{3}$ and $\mathrm{S}_{1} \mathrm{E}_{2} \mathrm{~A}_{3}$ and would provide these linear strings as inputs to the motor modules that deal with the programming of the movements needed to write them. According to this rationale, the timing of the production of $\mathrm{E}_{2}$ should be equivalent for the two words, because they have the same identity and order. In a different perspective, the way we produce the movements to write $E_{2}$ could depend on the linguistic status of the letter chunk in which it is embedded. In $s e a, \mathrm{E}_{2}$ cannot be dissociated from $a$, because it belongs to a specific ea letter chunk that represents the phoneme $/ \mathbf{i} / \mathrm{E}_{2}$ in set simply represents the phoneme $/ \varepsilon /$. This tendency to group small units into bigger chunks is a well-known phenomenon that is particularly efficient for memorization (cf. Jenkins $\&$ Russel, 1952). The idea that, in writing processes, we recover the spelling of words by activating letter chunks is therefore quite appealing. The goal of this study was to provide evidence that the timing of the production of $\mathrm{E}_{2}$ in set and sea should be different, because in set there is a one-to-one relationship between phonemes and letters, whereas in sea, this relationship is not straightforward and is more complex. If we generate letter chunks that represent phonemes, we could optimize the recall of spelling in a more linguistically oriented fashion.

When a letter represents a phoneme, it is referred to as a grapheme. Coltheart (1978) defined graphemes as the written representation of phonemes. One-letter graphemes such as $E_{2}$ in set are simple graphemes, and letter chunks such as EA in sea are complex graphemes. So, to write sea-a three-letter but two-grapheme word-we should activate $\mathrm{S}_{1} \mathrm{EA}_{2}$ and then "unwrap" the EA chunk into $\mathrm{E}$ and $\mathrm{A}$ for serial production. This conception of handwriting supposes that orthographic representations would not consist merely of linear letter strings encoding information on letter identity and order. They could be multilevel structures that encode information on letter chunks that obey phonological coherence.

This idea is not new and was introduced by Caramazza and Miceli in 1990 on the basis of neuropsychological data. These authors presented a case study of an Italian

S. Kandel, sonia.kandel@upmf-grenoble.fr 
patient with acquired dysgraphia. The brain damage produced a deficit at the graphemic output buffer. This temporary storage device regulates the lexical and nonlexical processing of abstract letter representations for spelling tasks and the more peripheral components of the writing sequence. The outcome of this study led them to conclude that words are symbolic entities that are stored in memory together with information on the various linguistic levels that compose them. Since this approach is inspired from phonological research, each level refers to a tier, which is the terminology used by phonologists (e.g., Clements \& Keyser, 1983). The first level encodes, of course, information on the identity of the letters that constitute the spelling of the word, but the second one stores information on their consonant or vowel status. Another level of representation refers to the syllabic structure of the word, with information on syllable boundary position. Other studies also showed that orthographic representations have a specific codification of double letters (McCloskey, Badecker, Goodman-Schulman, \& Aliminosa, 1994; Tainturier \& Caramazza, 1996). According to this view, $\mathrm{E}_{2}$ in $\mathrm{S}_{1} \mathrm{E}_{2} \mathrm{E}_{3}$ should also be different from the $\mathrm{E}_{2}$ in $\mathrm{S}_{1} \mathrm{E}_{2} \mathrm{~T}_{3}$ and $\mathrm{S}_{1} \mathrm{E}_{2} \mathrm{~A}_{3}$, leading to the following decomposition: $\mathrm{S}_{1} \mathrm{E}_{2} \mathrm{~T}_{3}, \mathrm{~S}_{1} \mathrm{EA}_{2}$, and $\mathrm{S}_{1} \mathrm{E}_{2}$ double. It should be pointed out that Caramazza and Miceli mentioned that the results "suggest that it is graphemic structure and not phonology that determines the distribution of errors" (p. 280). ${ }^{1}$

Particularly relevant for the purpose of this research was a more recent study with dysgraphic patients conducted by Tainturier and Rapp (2004) in English. Their patients' spelling errors revealed that orthographic representations encode information on two-letter graphemes that represent a single phoneme, like $p h=/ \mathbf{f} /$ in phone. This information is different from letter sequences that correspond to two phonemes, as in the consonant cluster $p l=/ \mathrm{pl} /$ in place. Their data indicate that complex graphemes have a unitary representation and are "unpacked" at the moment of serial production to specify letter identity and order. This conception of the spelling processes is in agreement with Houghton and Zorzi's (2003) connectionist model of spelling processes. They proposed two distinct representational levels, one for grapheme units and another for letter units. For example, to spell the word sea, the model processes $e a$ as a unit at the grapheme level, providing a more straightforward mapping from phonology to orthography than if there were a direct mapping from sounds to letters. The simulations of the spelling process were more accurate when both grapheme and letter levels were considered than when the grapheme level was excluded.

Research on typewriting revealed that letter-chunking strategies are also constrained by different kinds of sublexical units (Weingarten, 2005; Weingarten, Nottbusch, $\&$ Will, 2004). In typing movements, the accelerations and decelerations seem to be regulated by graphemic, syllabic, and morphological structures. Several studies revealed that interkey durations at the boundaries between graphemes, syllables, and morphemes were always longer than within these units. This points to orthographically regulated movement planning and has been observed with visual and auditory word presentations (Will, Nottbusch, \& Weingarten, 2006).

Finally, another line of research supporting the psychological reality of complex graphemes as processing units comes from experimental studies of visual word recognition in adults. Rey, Ziegler, and Jacobs (2000) asked English- and French-speaking participants to identify a target letter $a$ embedded in a complex grapheme (ea in beach) or in a word in which it appeared as a simple grapheme ( $a$ in place). The response times were systematically longer when the target letter was embedded in a complex grapheme than when embedded in a simple grapheme. The authors argued that response times were longer because it is harder to detect a target letter when it is embedded in a complex unit. The reading system has to split the unit into its constituents, which is more time consuming than for simple graphemes. Moreover, the authors showed that this effect could not be explained by the phonemic realization of the target letter. They replicated their results, keeping the phonology constant. They found shorter response times to detect $o$ in slope (simple grapheme) than in float (complex grapheme).

In sum, graphemes seem to mediate spelling and reading processes, supporting the idea that the handwriting production system could use grapheme units as well. This hypothesis is particularly appealing in French, because there are at least 34 graphemes of more than one letter (Catach, 1995). French phoneme-grapheme associations are less consistent than grapheme-phoneme ones (Ziegler, Jacobs, \& Stone, 1996), so the mapping from phonemes to graphemes to letters should be more efficient than that from phonemes to letters directly. The timing of handwriting production could be modulated by grapheme-like units, because they render sound-to-letter relationships more straightforward. Recent experimental studies of handwriting production conducted in French have provided evidence that phonological information such as syllable structure can regulate the way we write letter strings.

In Kandel, Álvarez, and Vallée (2006), adult participants wrote words on a digitizer that recorded the spatial and kinematic parameters of the handwriting movement. The words shared the initial letters but had different syllable boundaries (e.g., tra.ceur [tracer] and trac.tus [tract]; the dot indicates the syllable boundary). The participants had to write in uppercase letters and lift the pen between the letters. The idea underlying this task was that the duration of the intervals between the letters provides information on the timing of motor programming. To control for an eventual role of subvocal rehearsal, the participants had to write the words and perform a counting task out loud simultaneously. The outcome of this research revealed that the interletter intervals were longer between syllables (between $a$ and $c$ in tra.ceur) than within syllables (between $a$ and $c$ in trac.tus). The authors concluded that these duration differences revealed that the participants wrote the words by grouping the letters into syllable-like chunks. It is noteworthy that these differences cannot be 
accounted for in terms of reading processes - the visual presentation of the word on the screen - because this kind of syllable effect also appeared with written picture naming and dictation tasks (Álvarez, Cottrell, \& Afonso Hernández, 2009).

This interpretation of the duration differences follows from the rationale presented in Van Galen's (1991) model of handwriting production. It postulates that handwriting results from a series of processing levels organized in a hierarchical architecture. The intentions, semantic recovery, and syntactic construction modules are high-level processing modules that are common to speech and handwriting. They were essentially inspired by Levelt's (1989) model of speech production. Handwriting differs from speech at the spelling module. Then, there are three low-level processing modules-known as the motor modules - that are responsible for the selection of allographs, size control, and muscular adjustment. Our study focuses on the interaction between the spelling and motor modules. According to the model, the spelling module activates processing units that are whole words. This constitutes the input to the allographic module, which processes letter-sized units. Note that according to this view, there is no intermediate-grained unit between words and letters. In Van Galen's model, all the modules can be active simultaneously, but the higher order processing levels are always further ahead than the lower ones during the execution of a movement. They anticipate and process information related to forthcoming parts of the word while a current sequence is written. When various levels are active in parallel, and because processing capacities are limited, movement duration increases. The duration increases results from supplementary cognitive loads that are due to the simultaneous processing of different representational levels: the local parameters of the current letter (e.g., size, rotation direction, force) and spelling information on the forthcoming syllable. In this context, the interletter interval durations in Kandel, Álvarez, and Vallée (2006) were longer at the syllable boundary because the motor system anticipated the production of the following syllable. For the withinsyllable intervals, the movement to produce the syllable had already been programmed, so there was no need for further processing at this location. This syllable-bysyllable writing pattern is already present in French children since the first grade (Kandel, Hérault, Grosjacques, Lambert, \& Fayol, 2009; Kandel, Soler, Valdois, \& Gros, 2006; Kandel \& Valdois, 2006). Moreover, it was replicated with French words of various syllable lengths (Lambert, Kandel, Fayol, \& Espéret, 2008), as well as in Spanish (Álvarez et al., 2009).

In the present study we hypothesized that another way of introducing phonological coherence in handwriting would be to chunk a word's letters into grapheme-like processing units. Grapheme processing could constitute an intermediate level between syllable units and letters. Following the anticipatory rationale of Van Galen's (1991) handwriting model, grapheme units should be activated before the execution of the movement to produce its first letter. This activation should spread in a "cascaded" fashion, in parallel with the processing of lower levels that control local parameters, such as size or stroke direction

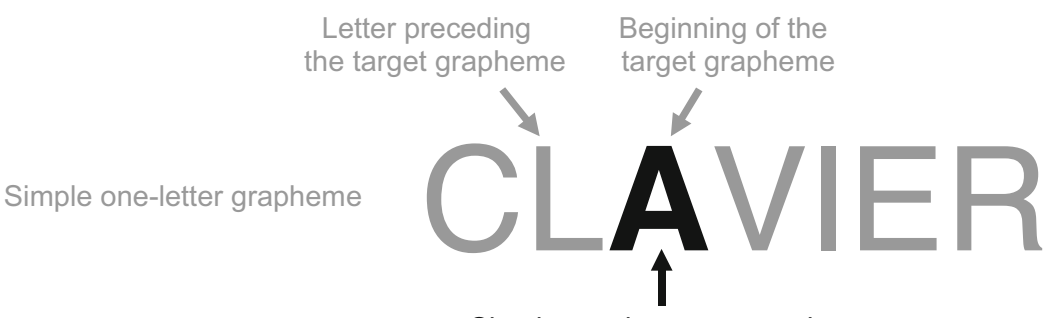

Simple grapheme processing

Complex two-letter grapheme

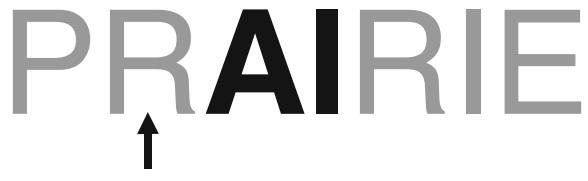

Complexity processing

Complex three-letter grapheme

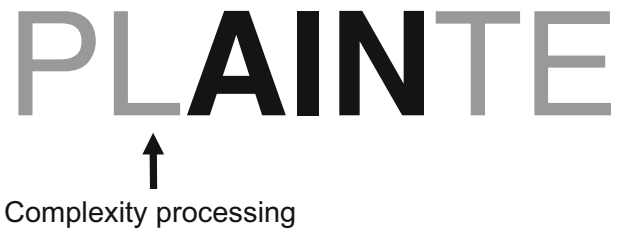

Figure 1. Schematic presentation of how we expect the writing system to process grapheme complexity at the letter preceding the target grapheme (e.g., CLAVIER, PRAIRIE, PLAINTE) and the beginning of the target grapheme (e.g., CLAVIER, PRAIRIE, PLAIINTE). 
of the letter(s) preceding the grapheme. The simultaneous processing of information of different representational levels should be time consuming and, therefore, result in longer movement durations in the preceding letter(s). If graphemes are indeed processing units in handwriting, complex graphemes should yield longer movement durations than should simpler ones. In this experiment, we varied the degree of complexity of different French graphemes. Grapheme complexity was determined by the number of letters that represented a phoneme. We used the letters $\mathrm{A}$ and $\mathrm{E}$ and then added the letters I and $\mathrm{N}$ to increase grapheme size (A, AI, AIN OR E, EI, EIN). The graphemes were embedded in words and consisted of one, two, or three letters (see Figure 1).

More precisely, the participants wrote words containing one-letter simple graphemes $(\mathrm{A}=/ \mathrm{a} / \mathrm{in}$ CLLVIER, [klavje], keyboard; and $\mathrm{E}=/ \mathrm{a} /$ in RELANCE [Rəlãs], revival). Regarding complex graphemes, in the two-letter grapheme condition A and E were associated to I such that AI $=/ \varepsilon /$ (e.g., PRAIRIE, [preri], meadow) and EI $=/ \varepsilon /$ (e.g., NEIGEUX [nezø], snowy). In the three-letter condition, $\mathrm{AI}$ and EI were associated to $\mathrm{N}$ such that $\mathrm{AIN}=/ \tilde{\varepsilon} /$ (e.g., PLAINTE [plẽt], complaint) and EIN $=/ \tilde{\varepsilon} /$ (e.g.,

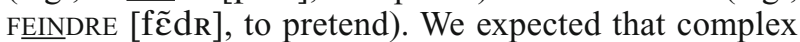
graphemes would require more processing than would simple graphemes. This should be reflected by longer durations of the letter preceding and the first letter of the target grapheme. We also predicted a gradient effect of grapheme complexity. The letter durations for the threeletter graphemes should be longer than those for the twoletter graphemes.

\section{METHOD}

\section{Participants}

Thirty-six right-handed students from the Université Pierre Mendès France participated in the experiment. The participants were from 20 to 26 years old (mean age, 23 years). There were 21 women and 15 men. They were all native French speakers and unaware of the purpose of the experiment. They all had normal or correctedto-normal vision and no motor or hearing disorders. They received course credit for participating in the experiment.

\section{Materials}

The target graphemes included the letters A and E (see the Appendix). In the one-letter condition, A refers to the phoneme /a/ and $\mathrm{E}$ to the phoneme $/ \mathrm{a} /$. The addition of a letter in each condition changed the phonologic value of the grapheme. In the two-letter condition, A and $\mathrm{E}$ were associated to $\mathrm{I}$ such that $\mathrm{AI}$ and $\mathrm{EI}=/ \varepsilon /$. In the three-letter condition, AI and EI were associated to $\mathrm{N}$ such that AIN and EIN $=/ \tilde{\varepsilon} /$. There were 30 word triplets (e.g., CLAVIER, PRAIRIE, PLAINTE). The A or E in the target grapheme appeared at the same position in each triplet (e.g., A appears in Position 3 in the three words). The words in each triplet had the same number of letters. The words were matched for word frequency and bigram frequency between the letter preceding the grapheme and the grapheme (e.g., bigrams LA in CLAVIER, RA in PRAIRIE, and LA in PLAINTE). According to the Lexique 2 French Data Base (New, Pallier, Ferrand, \& Matos, 2001; www .lexique.org), word frequency was 16.20 occurrences per million for the one-letter grapheme words, 9.37 occurrences per million for the two-letter grapheme words $[t(30)=0.73, p=.53]$, and 24.25 occurrences per million for the three-letter grapheme words $[t(30)=0.38$, $p=.70]$. The mean bigram frequencies between the letter preceding the grapheme and A and E was 1,022 for the one-letter grapheme words, 995 for the two-letter grapheme words $[t(30)=0.19, p=$ $.84]$, and 950 for the three-letter grapheme words $[t(30)=0.33, p=$ .73; Content \& Radeau, 1988]. All the letters preceding the target grapheme were one-letter graphemes, except for three words: $\mathrm{CH}$ in CHEVILLE, LL in ALLEMANDE, and TT in ATTEINDRE.

\section{Procedure}

The participants had to write the word they saw on the screen of the computer on the digitizer (Wacom Intuos 2; sampling frequency, $200 \mathrm{~Hz}$; accuracy, $0.02 \mathrm{~mm}$ ). They had to write with a special pen (Intuos Inking Pen) on a lined paper that was stuck to the digitizer (vertical limit $=8 \mathrm{~mm}$, horizontal limit $=17 \mathrm{~cm}$ ). The experiment was conducted with Ductus, a handwriting software package developed in our laboratory for the study of handwriting production (Guinet \& Kandel, 2010). The words appeared at the center of the screen of a laptop, written in uppercase Times New Roman, font size 18 . Before the presentation of the word, there was an auditory signal that indicated the beginning of the trial and a fixation point for $200 \mathrm{msec}$. As in previous studies on adult handwriting production, the participants had to write the words in uppercase letters and lift the pen between each letter in a small wrist upward-downward movement (Álvarez et al., 2009; Bogaerts, Meulenbroek, \& Thomassen, 1996; Kandel, Álvarez, \& Vallée, 2006, 2008). The reason for the uppercase letters instruction is that, unlike cursive handwriting, the beginning and end of the letters are very clear.

The participants practiced by writing their names several times, until they thought that they could write "spontaneously" in uppercase letters. There were two practice items before the beginning of the experiment. The participants had to start writing as soon as they saw the word and write at a normal speed. When the participant finished writing a word, the experimenter clicked on a button to present the following word. The participants were tested individually in a quiet room. We presented the 90 words in random order in three blocks of 30 stimuli. The experiment lasted between 40 and $50 \mathrm{~min}$.

\section{Data Processing and Analysis}

Ductus also has a semiautomatic handwriting analysis module (see Guinet \& Kandel, 2010, for information on the analysis procedure). The data were smoothed with a Finite Impulse Response filter (Rabiner \& Gold, 1975) with a 12-Hz cutoff frequency. Then we segmented the words into their letter constituents so we could obtain data on the timing of the movement that produced each letter. We focused on letter duration because it is a very sensitive measure that is widely used in studies investigating the linguistic components of handwriting production (Bogaerts et al., 1996; Meulenbroek \& Van Galen, 1986, 1988, 1989, 1990; Mojet, 1991; Orliaguet \& Boë, 1993; Van Galen, 1991; Van Galen, Meulenbroek, \& Hylkema, 1986; Zesiger, Mounoud, \& Hauert, 1993; Zesiger, Orliaguet, Boë, \& Mounoud, 1994). Letter duration refers to the time the participants took to write a letter. We measured the duration of the letter that preceded the target grapheme to examine whether grapheme complexity is processed before one starts to write it. For instance, in CLAVIER, we measured the time the participant took to write the $\mathrm{L}$, because it is the letter that precedes the A. We also measured the time the participant took to write A, because it appears in the three targets (A, AI, AIN) and constitutes the beginning of the grapheme. We also measured the duration of I in the complex graphemes AI and AIN.

Since we had to compare the durations of letters of different sizes (e.g., L has two strokes and A has three strokes), we normalized the absolute duration values with respect to the number of strokes per letter (see Bogaerts et al., 1996, for an explanation on the rationale underlying this kind of procedure). For example, if the duration of L was $300 \mathrm{msec}$ and that of A was $450 \mathrm{msec}$, we $\operatorname{did} 300 / 2=150$ and $450 / 3=150$. The resulting stroke durations were 150 for both letters. Thus, we considered that there was no difference between the durations of the two letters.

Since there is no standard definition for stroke segmentation for handwritten uppercase letters - as there is for lowercase cursive let- 

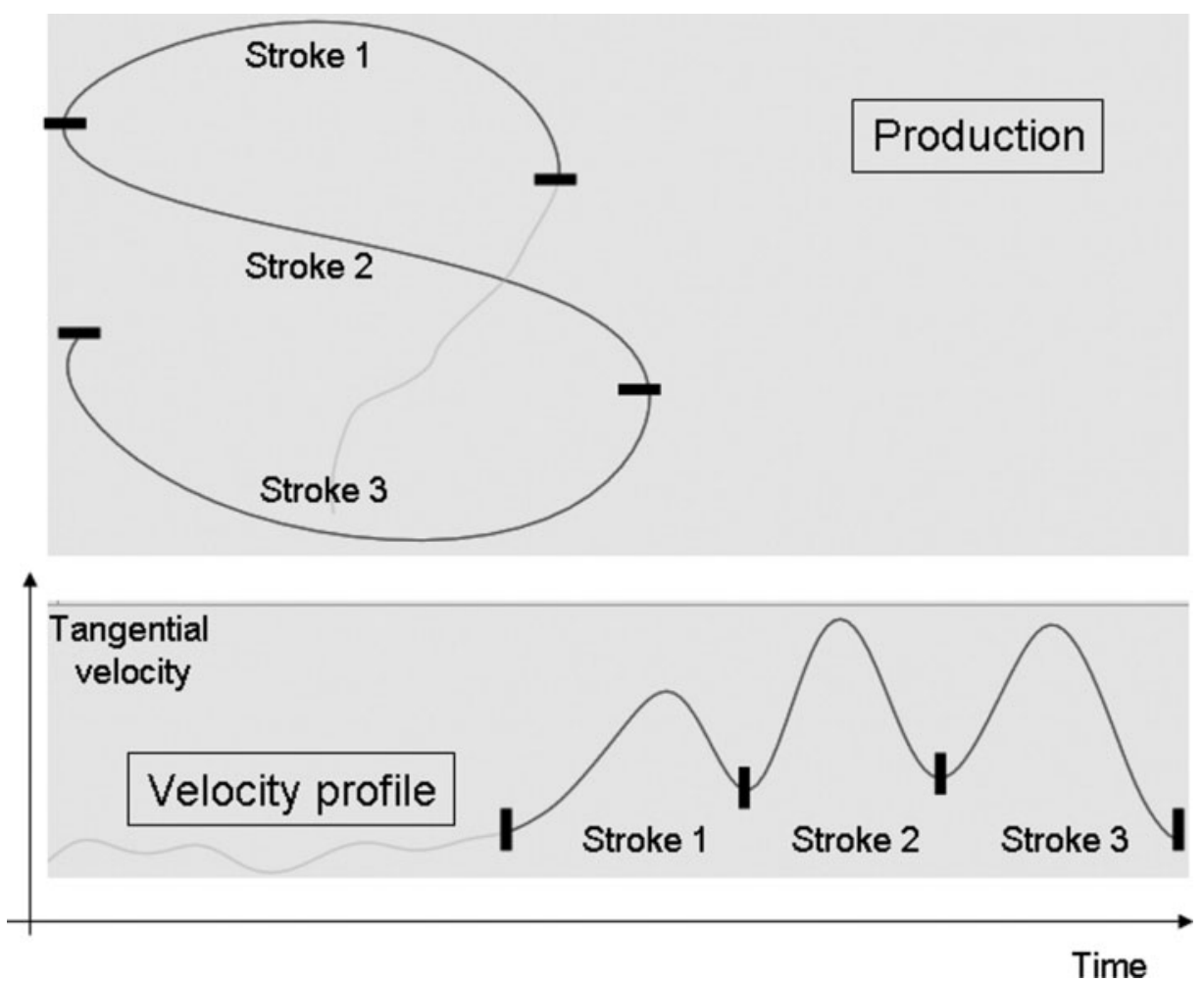

Figure 2. Example of stroke segmentation of the letter "s." The upper part concerns the letter trace (production), and the lower part the velocity profile. The bold lines show the beginning and/ or end of a stroke in the letter trace and velocity profile. The shaded lines represent the in-air movement that is done before one starts to write.

ters (see Meulenbroek \& Van Galen, 1990)—we determined letter segmentation ourselves on the basis of the number of strokes needed to write a letter. For letters that are composed only of straight lines (e.g., L, T, F, E), the procedure was quite simple: A has three bars, so we divided the absolute duration of the writing sequence by three. For the uppercase letters of the alphabet with curved traces, such as C, S, R, or $\mathrm{O}$, we conducted a previous stroke segmentation analysis based on the tangential velocity minima in the velocity profile (see Figure 2).

This criterion for stroke segmentation is classical in studies of motor control and has been used in many studies in handwriting (see Orliaguet, Kandel, \& Boë, 1997, for an example). As Figure 2 shows, an s, for instance, has three strokes. So if the participant produced the $\mathrm{s}$ in $300 \mathrm{msec}$, the stroke duration would result in $300 / 3=$ $100 \mathrm{msec}$.

\section{RESULTS}

The data on letter stroke durations were submitted to an ANOVA analyzed both by participants $\left(F_{1}\right)$ and by items $\left(F_{2}\right)$, with letter position (letter preceding the target grapheme, first letter of the target grapheme) and grapheme length (one, two, and three letters) as within-participants factors. Figure 3 shows the mean stroke durations of the letter preceding the grapheme (e.g., CLAVIER, PRAIRIE, PLAINTE) and of the first letter of the target grapheme (e.g., CLAVIER, PRAIRIE, PLAIINTE) in words containing one-, two-, and three-letter graphemes.

The analysis revealed a main effect of letter position $\left[F_{1}(1,35)=18.35, p<.001 ; F_{2}(1,29)=6.78, p<\right.$
$.01]$. There was also a main effect of grapheme length $\left[F_{1}(2,70)=62.45, p<.001 ; F_{2}(2,58)=18.42, p<\right.$ $.001]$. The global durations for one-letter graphemes were shorter than those for two-letter graphemes, but the differences did not reach significance in the by-items analysis $\left[F_{1}(1,35)=135.24, p<.001 ; F_{2}(1,29)=3.11, p>.05\right]$. The durations for two-letter graphemes were shorter than those for three-letter graphemes $\left[F_{1}(1,35)=4.76, p<\right.$ $\left..05 ; F_{2}(1,29)=16.01, p<.001\right]$. They were shorter for one- than for three-letter graphemes $\left[F_{1}(1,35)=99.53\right.$, $\left.p<.001 ; F_{2}(1,29)=22.64, p<.001\right]$. These differences are still significant after a Bonferroni correction. The interaction between letter position and grapheme length was significant $\left[F_{1}(2,70)=69.07, p<.001 ; F_{2}(2,58)=\right.$ $17.01, p<.001]$.

The durations of the letters preceding the target graphemes (e.g., CLAVIER, PRAIRIE, PLAINTE) were modulated by grapheme length. The stroke durations were shorter for one- than for two-letter graphemes, although the differences did not reach significance in the by-items analysis $\left[F_{1}(1,35)=225.04, p<.001 ; F_{2}<1\right] .^{2}$ The stroke durations were shorter for two- than for three-letter graphemes $\left[F_{1}(1,35)=9.14, p<.01 ; F_{2}(1,87)=26.15, p<.001\right]$. The durations were shorter for one- than for three-letter graphemes $\left[F_{1}(1,35)=161.60, p<.001 ; F_{2}(1,29)=\right.$ $32.31, p<.001]$. These differences were still significant after a Bonferroni correction. 


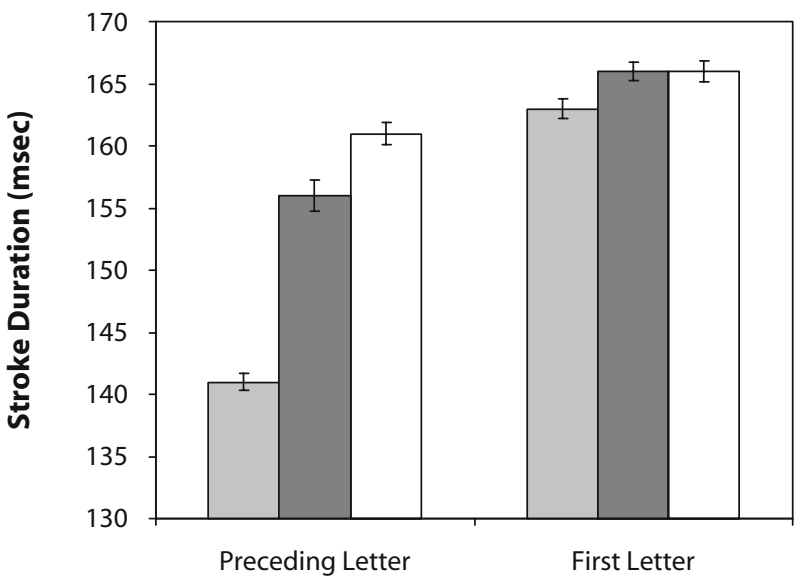

Letter Position

$\square 1$ letter (A, E) $\square 2$ letters (Al, El) $\square 3$ letters (AIN, EIN)

Figure 3. Mean stroke durations (in milliseconds) of the letter preceding the target grapheme (e.g., CLLAVIER, PRAIRIE, PLAINTE) and of the letters A and $\mathrm{E}$ (e.g., CLAVIER, PRAIRIE, PLAINTE) in words containing one-, two-, and three-letter graphemes. Standard errors are represented in the figure by the error bars attached to each column.

The durations of the first letters of the target graphemes (e.g., CLAVIER, PRAIRIE, PLAINTE) were shorter for one- than for two-letter graphemes $\left[F_{1}(1,35)=8.02, p<\right.$ $\left..01 ; F_{2}(1,29)=9.41, p<.01\right]$. In contrast, the differences were not significant between two- and three-letter graphemes (both $F \mathrm{~s}<1$ ). The durations were shorter for one- than for three-letter graphemes $\left[F_{1}(1,35)=10.08\right.$, $\left.p<.01 ; F_{2}(1,29)=14.47, p<.001\right]$. These differences were significant after a Bonferroni correction. This suggests that most of the processing of grapheme length was done on the letter preceding the grapheme.

The analysis for one-letter graphemes indicated that the durations for the preceding letters ( $\mathrm{L}$ in CLAVIER) were shorter than those for the first letters of the target graphemes (A in CLAVIER) $\left[F_{1}(1,35)=53.30, p<.001\right.$; $\left.F_{2}(1,29)=9.95, p<.01\right]$. This suggests that most of the processing of simple graphemes is done online, while the letter itself is produced. For the two-letter graphemes, the durations for the preceding letters (R in PRAIRIE) were shorter than those for the first letters of the target graphemes (A in PRAIRIE), but the differences were not significant in the by-items analysis $\left[F_{1}(1,35)=11.19, p<.001\right.$; $\left.F_{2}(1,29)=1.63, p>.05\right]$. Finally, for the three-letter graphemes, the durations for the preceding letters ( $\mathrm{L}$ in PLAINTE) were shorter than those for the first letters of the target graphemes (A in PLAINTE) $\left[F_{1}(1,35)=9.83\right.$, $\left.p<.01 ; F_{2}(1,29)=14.26, p<.001\right]$. This supports the idea that grapheme length is processed mostly at the letter preceding the target grapheme. Nevertheless, there is still some processing at the first letter of the target grapheme.

The mean stroke durations of the I in complex graphemes was $153 \mathrm{msec}$ for the two-letter graphemes (I in
PRAIRIE) and $155 \mathrm{msec}$ for the three-letter graphemes (I in PLAINTE). We conducted another ANOVA to compare the two- and three-letter complex graphemes on the duration of I. The data were analyzed both by participants $\left(F_{1}\right)$ and by items $\left(F_{2}\right)$, with grapheme length (two and three letters) as the within-participants factor. The analysis of the duration of the I did not reveal any significant difference $\left[F_{1}<1 ; F_{2}(1,58)=1.17, p>.05\right]$. This result confirms the idea that the handwriting systems stops processing grapheme length at the letter preceding the target grapheme.

\section{DISCUSSION}

This research investigated whether graphemic complexity regulates the timing of handwriting production. Adult participants wrote French words (e.g., CLAVIER, PRAIRIE, PLAINTE) containing an embedded one-letter grapheme (e.g., A), two-letter grapheme (e.g., AI), and three-letter grapheme (e.g., AIN). By means of a digitizer and specific software, we focused on an online measure that is particularly sensitive to linguistic effects on handwriting production-namely, letter duration. We observed that grapheme complexity regulated the timing of letter production, since letter duration increased with grapheme length. One-letter graphemes required less processing than did two-letter graphemes, which, in turn, required less processing than did three-letter graphemes (i.e., [L and A in CLAVIER] $<$ [R and $\mathrm{A}$ in PRAIRIE] $<\mathrm{L}$ and $\mathrm{A}$ in PLAINTE]). The results also revealed that letter duration was shorter when the letter preceding the target grapheme was written than when its first letter was (e.g., in CLAVIER, $\mathrm{L}<\mathrm{A}$; in PRAIRIE, $\mathrm{R}<\mathrm{A}$; in PLAINTE, $\mathrm{L}<\mathrm{A}$ ). It is thus likely that most, but not all, of the processing of the grapheme is done when one begins to write it.

The significant interaction between letter position and grapheme length indicated that the processing of simple and complex graphemes occurs at different times. The results for the letter preceding the target grapheme (e.g., L in CLAVIER, $R$ in PRAIRIE, $L$ in PLAINTE) showed that stroke durations increased as the number of letters in the grapheme to be written increased. They were longer for three-letter graphemes than those for two-letter graphemes, which, in turn, were longer than those for one-letter graphemes. The fact that we observed this one-letter $<$ two-letter $<$ threeletter duration tendency at the letter preceding the grapheme confirms the idea that grapheme complexity starts being processed before one begins to write the grapheme. It should be noted, however, that the one-letter $<$ twoletter difference did not reach significance in the by-items analysis. It is therefore likely that the most relevant processing at this location concerns the gradient of complexity (i.e., the two-letter $<$ three-letter duration difference). This idea is supported by the fact that when the results for A or E (e.g., A in CLAVIER, A in PRAIRIE, A in PLAINTE) were examined, the durations for two- and three-letter graphemes did not differ - as for the durations of letter Iindicating that the gradient of complexity is processed before the production of the grapheme begins. Finally, the 
significant differences between one-letter graphemes with respect to two- and three-letter graphemes in the letters A and E suggest that the timing of simple grapheme production differs from complex grapheme production essentially when the grapheme begins.

To summarize, simple graphemes seem to be processed when the letter begins. In contrast, the system processes complex graphemes and, particularly, the gradient of complexity before starting to write them. This phenomenon is essentially observed at the letter preceding the target grapheme (see Figure 1). The data indicated that the handwriting system anticipates the processing of complex graphemes at the same time that it is processing the local parameters (e.g., letter size, stroke direction) that regulate the movements to produce the letter preceding the grapheme. The parallel processing of various representational levels - the spelling module and the other motor modules - is more time consuming than the mere processing of local parameters and constitutes, in Van Galen's (1991) terms, a supplementary cognitive load. This model predicts that higher order levels are still active during the processing of the word and, particularly, during the production of the first letters. In the context of the present study, the high order level refers to the spelling module that processes grapheme complexity, whereas a more peripheral level refers to the local parameters needed to execute the letter. Moreover, the information on grapheme complexity regulates the writing process all throughout the movements that precede the gesture that actually produces the grapheme. This appears quite clearly in the duration of the letter that is located before the grapheme. This pattern of results is in line with the idea that central and peripheral processes function in a cascaded fashion (Álvarez et al., 2009; Delattre, Bonin, \& Barry, 2006; Kandel, Spinelli, Guerassimovitch, \& Álvarez, 2010). In other words, grapheme processing starts before the processing of the motor parameters required to produce the grapheme itself and cascades into the processes that regulate the local aspects of letter production at the first letter of the grapheme.

This investigation provides further evidence that when we have to write a word, we activate orthographic representations that encode much more information than letter identity and order, as Van Galen's (1991) model postulates. Apart from information on syllable-like units (Kandel, Álvarez, \& Vallée, 2006) and morphological structure (Kandel et al., 2008; Kandel et al., 2010), they encode information on grapheme-like units as well. If the handwriting system encoded only information on letter identity and order, writing an A in CLAVIER, PRAIRIE, and PLAINTE should be identical in the three cases and, thus, have similar durations. Our results contradict this statement. Grapheme complexity modulates the timing of the production of the A, suggesting that orthographic representations are not limited to letter identity and order. This multilevel conception of orthographic representations is in line with neuropsychological studies that suggest that spelling processes exploit information on grapheme structure (Tainturier \& Rapp, 2004). This way of grouping letters into chunks seems to optimize spelling recall and facilitate the programming of motor outputs. Therefore, higher order linguistic units that are smaller than the word but bigger than letters modulate the timing of handwriting production. This multilevel structure seems to regulate motor production in adults but also plays a major role in the elaboration of spelling processes in writing acquisition (Kandel et al., 2009; Kandel \& Valdois, 2006). Van Galen's model should therefore be revisited, and new models of handwriting production should include intermediate-grained processing units between words and letters.

\section{AUTHOR NOTE}

This research was supported by a grant from the Région Rhône-Alpes (Cluster Handicap, Viellissement et Neurosciences) to S.K. We thank Helena Guerassimovitch for her help with the data analysis. Correspondence concerning this article should be addressed to S. Kandel, Laboratoire de Psychologie et NeuroCognition (CNRS UMR 5105), Université Pierre Mendès France, B.P. 47, 38040 Grenoble Cedex 09, France (e-mail: sonia.kandel@upmf-grenoble.fr).

\section{REFERENCES}

Álvarez, C. J., Cottrell, D., \& Afonso Hernández, O. (2009). Writing dictated words and picture names: Syllabic boundaries affect execution in Spanish. Applied Psycholinguistics, 30, 205-223.

Bogaerts, H., Meulenbroek, R. G. J., \& Thomassen, A. J. W. M. (1996). The possible role of the syllable as a processing unit in handwriting. In M. L. Simner, C. G. Leedham, \& A. J. W. M. Thomassen (Eds.), Handwriting and drawing research: Basic and applied issues (pp. 115-126). Amsterdam: IOS Press.

Caramazza, A., \& Miceli, G. (1990). The structure of graphemic representations. Cognition, 37, 243-297.

CAtach, N. (1995). L'orthographe française. Paris: Nathan.

Clements, G. N., \& Keyser, S. J. (1983). CV phonology: A generative theory of the syllable. Cambridge, MA: MIT Press.

Coltheart, M. (1978). Lexical access in simple reading tasks. In G. Underwood (Ed.), Strategies of information processing (pp. 151216). London: Academic Press.

Content, A., \& Radeau, M. (1988). Données statistiques sur la structure orthographique du Français. Cahiers de Psychologie Cognititve, 8, 399-404.

Delattre, M., Bonin, P., \& Barry, C. (2006). Written spelling to dictation: Sound-to-spelling regularity affects both writing latencies and durations. Journal of Experimental Psychology: Learning, Memory, \& Cognition, 32, 1330-1340.

Guinet, E., \& Kandel, S. (2010). Ductus: A software package for the study of handwriting production. Behavior Research Methods, $\mathbf{4 2}$, 326-332.

Houghton, G., \& Zorzi, M. (2003). Normal and impaired spelling in a connectionist dual-route architecture. Cognitive Neuropsychology, 20, 115-162.

Jenkins, J. J., \& Russel, W. A. (1952). Associative clustering during recall. Journal of Abnormal \& Social Psychology, 47, 818-821.

Kandel, S., Álvarez, C. J., \& VAllée, N. (2006). Syllables as processing units in handwriting production. Journal of Experimental Psychology: Human Perception \& Performance, 32, 18-31.

Kandel, S., Álvarez, C. J., \& Vallée, N. (2008). Morphemes also serve as processing units in handwriting production. In M. Baciu (Ed.), Neuropsychology and cognition of language behavioural, neuropsychological and neuroimaging studies of spoken and written language (pp. 87-100). Kerala, India: Research Signpost.

Kandel, S., Hérault, L., Grosjacques, G., Lambert, E., \& Fayol, M. (2009). Orthographic vs. phonologic syllables in handwriting production. Cognition, 110, 440-444.

Kandel, S., Soler, O., Valdois, S., \& Gros, C. (2006). Graphemes as motor units in the acquisition of writing skills. Reading \& Writing, 19, 313-337.

Kandel, S., Spinelli, E., Guerassimovitch, H., \& Álvarez, C. (2010). Early and late morphological effects in handwriting: Evidence for cascaded processing. Manuscript submitted for publication. 
KANDEL, S., \& VAldoIs, S. (2006). Syllables as functional units in a copying task. Language \& Cognitive Processes, 21, 432-452.

Lambert, E., KAndel, S., FAyOL, M., \& Espéret, E. (2008). The effect of the number of syllables when writing poly-syllabic words. Reading \& Writing: An Interdisciplinary Journal, 21, 859-883.

Levelt, W. J. M. (1989). Speaking: From intention to articulation. Cambridge, MA: MIT Press.

McCloskey, M., Badecker, W., Goodman-Schulman, R. A., \& AlIMINOSA, D. (1994). The structure of graphemic representations in spelling: Evidence from a case of acquired dysgraphia. Cognitive Neuropsychology, 11, 341-392.

Meulenbroek, R. G. J., \& Van Galen, G. P. (1986). Movement analysis of repetitive behavior of first, second and third grade primary school children. In H. S. R. Kao, G. P. Van Galen, \& R. Hoosein (Eds.), Graphonomics: Contemporary research in handwriting (pp. 71-92). Amsterdam: North-Holland.

Meulenbroek, R. G. J., \& VAn Galen, G. P. (1988). The acquisition of skilled handwriting: Discontinuous trends in kinematic variables. In A. M. Cooley \& J. R. Beech (Eds.), Cognition and action in skilled behavior (pp. 273-281). Amsterdam: North-Holland.

Meulenbroek, R. G. J., \& Van Galen, G. P. (1989). The production of connecting strokes in cursive writing: Developing co-articulation in 8 to 12 year-old children. In R. Plamondon, C. Y. Suen, \& M. L. Simner (Eds.), Computer recognition and human production of handwriting (pp. 105-118). Singapore: World Scientific.

Meulenbroek, R. G. J., \& Van Galen, G. P. (1990). Perceptual-motor complexity of printed and cursive letters. Journal of Experimental Education, 58, 95-110.

MoJet, W. (1991). Characteristics of developing handwriting skills in elementary education. In J. Wann, A. M. Wing, \& N. Søvik (Eds.), Development of graphic skills (pp. 53-75). London: Academic Press.

New, B., Pallier, C., Ferrand, L., \& Matos, R. (2001). Une base de données lexicales du français contemporain: Lexique. L'Année Psychologique, 101, 447-462. Available at www.lexique.org.

Orliaguet, J. P., \& Bö̈, L. J. (1993). The role of linguistics in the speed of handwriting movements. Acta Psychologica, 82, 103-113.

Orliaguet, J.-P., Kandel, S., \& Bö̈, L.-J. (1997). Visual perception of cursive handwriting: Influence of spatial and kinematic information on the anticipation of forthcoming letters. Perception, 26, 905-912.

Rabiner, L. R., \& Gold, B. (1975). Theory and application of digital signal processing. Englewood Cliffs, NJ: Prentice Hall.

Rey, A., Ziegler, J. C., \& JACOBS, A. M. (2000). Graphemes are perceptual reading units. Cognition, 75, B1-B12.
Tainturier, M. J., \& Caramazza, A. (1996). The status of double letters in graphemic representations. Journal of Memory \& Language, 36, 53-73.

TAinturier, M. J., \& Rapp, B. (2004). Complex graphemes as functional spelling units: Evidence from acquired dysgraphia. Neurocase, 10, 122-131.

VAn Galen, G. P. (1991). Handwriting: Issues for a psychomotor theory. Human Movement Science, 10, 165-191.

Van Galen, G. P., Meulenbroek, R. G., \& Hylkema, H. (1986). On the simultaneous processing of words, letters and strokes in handwriting: Evidence for a mixed linear and parallel model. In H. S. R. Kao, G. P. Van Galen, \& R. Hoosain (Eds.), Graphonomics: Contemporary research in handwriting (pp. 5-20). Amsterdam: North-Holland.

Weingarten, R. (2005). Subsyllabic units in written word production. Written Language \& Literacy, 8, 43-61.

Weingarten, R., Nottbusch, G., \& Will, U. (2004). Morphemes, syllables, and graphemes in written word production. In T. Pechmann \& C. Habel (Eds.), Multidisciplinary approaches to language production (pp. 529-572). Berlin: Mouton de Gruyter.

Will, U., Nottbusch, G., \& Weingarten, R. (2006). Linguistic units in word typing: Effects of word presentation modes and typing delay. Written Language \& Literacy, 9, 156-173.

Zesiger, P., Mounoud, P., \& Hauert, C. A. (1993). Effects of lexicality and trigram frequency on handwriting production in children and adults. Acta Psychologica, 82, 353-365.

Zesiger, P., Orliaguet, J. P., Bö̈, L. J., \& Mounoud, P. (1994). The influence of syllabic structure in handwriting and typing production. In C. Faure, G. Lorette, \& A. Vinter (Eds.), Advances in handwriting and drawing: A multidisciplinary approach (pp. 389-401). Paris: Europia.

Ziegler, J. C., JACoBS, A. M., \& Stone, G. O. (1996). Statistical analysis of the bidirectional inconsistency of spelling and sound in French. Behavior Research Methods, Instruments, \& Computers, 28, 504-515.

\section{NOTES}

1. Italics are in the original text by Caramazza and Miceli (1990).

2. The lack of $F_{2}$ significance seems to be due to three embedded E word pairs (CHEVILLE/OREILLER, CIMETIËRE/ENSEIGNER, SAUVEGARDE/ GROSEILLE) where the duration tendency is inversed. Note that the oneletter grapheme E corresponds to the schwa $(/ \mathrm{\partial} /)$, which is always deleted in CIMETIËRE / simtjeR/ and SAUVEGARDE /sovgaRd/ and can also be deleted occasionally in CHEVILLE / $\int \mathrm{vij} /$ or / $\int \partial v i j /$. 
APPENDIX

Words Used in the Experiment in One-, Two-, and Three-Letter Grapheme Conditions

\begin{tabular}{|c|c|c|c|c|c|c|c|c|}
\hline \multicolumn{3}{|c|}{ One-Letter Grapheme $\mathrm{A}=/ \mathrm{a} /, \mathrm{E}=/ \mathrm{a} /$} & \multicolumn{3}{|c|}{ Two-Letter Grapheme AI and EI $=/ \varepsilon /$} & \multicolumn{3}{|c|}{ Three-Letter Grapheme AIN and EIN $=/ \tilde{\varepsilon} /$} \\
\hline \multirow[b]{2}{*}{ Word } & \multicolumn{2}{|c|}{ Frequency } & \multirow[b]{2}{*}{ Word } & \multicolumn{2}{|c|}{ Frequency } & \multirow[b]{2}{*}{ Word } & \multicolumn{2}{|c|}{ Frequency } \\
\hline & Word & Bigram & & Word & Bigram & & Word & Bigram \\
\hline Clavier (keyboard) & 3.77 & 480 & Prairie (meadow) & 9.29 & 1,100 & Plainte (complai & 13.84 & 480 \\
\hline Travaux (works) & 137.97 & 1,100 & Traiter (to process) & 24.45 & 00 & Crainte (fear) & 35.39 & 1,100 \\
\hline Marcher (to walk) & 47.87 & 1,679 & Baigner (to bathe) & 5.42 & 221 & Vaincre (to win) & 12.29 & 155 \\
\hline Gratiner (to broil) & 0.06 & 1,100 & Graisser (to lubricate) & 0.84 & 1,100 & Plaindre (to complain) & 14.65 & 480 \\
\hline Graviers (gravel) & 3.00 & 1,100 & Fraisier (strawberry pl.) & 0.29 & 1,100 & Craindre (to fear) & 15.55 & 1,100 \\
\hline Blagueur (joker) & 0.42 & 480 & Traiteur (catering) & 0.68 & 1,100 & Craintif (fearful) & 2.03 & 1,100 \\
\hline Maquette (model) & 2.19 & 1,679 & Vaisseau (vessel) & 6.16 & 155 & Saindoux (lard) & 4.87 & 1,189 \\
\hline Largesse (generosity) & 0.48 & 3,208 & Paisible (peaceful) & 15.52 & 2,626 & Sainteté (holiness) & 4.48 & 1,189 \\
\hline Japonaise (Japanese) & 4.32 & 203 & Baignoire (bathtub) & 7.19 & 221 & Vainqueur (winner) & 9.19 & 155 \\
\hline Batailler (to battle) & 0.48 & 221 & Raisonner (to reason) & 4.90 & 338 & Maintenir (to keep) & 33.03 & 1,679 \\
\hline Vacancier (on holidays) & 0.13 & 155 & Vaisselle (tableware) & 15.71 & 155 & Maintient (keeps) & 8.48 & 1,679 \\
\hline Cátholique (catholic) & 24.35 & 517 & Faiblement (weakly) & 12.03 & 1,087 & Maintenant (now) & 367.39 & 1,679 \\
\hline Ordinateur (computer) & 2.97 & 351 & Contraires (opposites) & 7.84 & 1,100 & Contrainte (constraint) & 16.06 & 1,100 \\
\hline Compassion (compassion) & 4.26 & 247 & Fantaisies (fantasies) & 2.55 & 595 & Convaincre (to convince) & 16.84 & 294 \\
\hline Obligatoire (compulsory) & 18.42 & 179 & Complaisant (obliging) & 1.52 & 480 & Contraindre (to constrain) & 4.39 & 1,100 \\
\hline Relance (revival) & 1.45 & 1,255 & Neigeux (snowy) & 1.00 & 1,793 & Feindre (to pretend) & 2.97 & 227 \\
\hline Sémoule (semolina) & 0.71 & 2,399 & Beignet (fritte & 0.29 & 233 & Geindre (moan) & 1.23 & 125 \\
\hline Secousse (jerk) & 5.06 & 2,399 & Peignoir (bathrob & 7.52 & 1,047 & Teinture (dye) & 2.74 & 662 \\
\hline Relation (relation) & 48.58 & 1,255 & Seigneur (lord) & 35.87 & 2,399 & re (belt) & 20.87 & 2,620 \\
\hline Regarder (to see) & 95.39 & 1,255 & Meilleur (best) & 52.32 & 969 & Peinture (paint) & 53.68 & 1,047 \\
\hline Crevasse (crev & & & Freinage & 4.90 & & Ereinter & 0.13 & 1,100 \\
\hline Cheville (ankle) & & 403 & Oreiller ( & 13.61 & & Eteindre & 10.87 & 1,234 \\
\hline Allemande (Germa & 25.87 & 1,042 & to wake up) & 16.35 & 949 & reach) & 53.13 & 1,234 \\
\hline Cimetière (cemetery) & 21.68 & & Ense & 9.90 & 78 & Dé & 0.71 & 253 \\
\hline Gisements & 4.81 & 780 & Baleinier (whaler) & 0.13 & 1,042 & Déte & 0.35 & 1,234 \\
\hline Sauvegarde (protection) & 4.19 & 949 & Groseilles (gooseberrie & 0.94 & 780 & Enfreindre & 0.94 & 1,100 \\
\hline Dangereuse (dangerous) & 11.23 & 257 & Merveilles (wonders) & 7.39 & 949 & Astreindre (to compel) & 0.84 & 1,100 \\
\hline Secouriste (rescuer) & 0.10 & 2,399 & Seigneurie (lordship) & 3.32 & 2,399 & Teinturier (dyer) & 0.81 & 662 \\
\hline Grincements (gnashing) & 1.65 & 326 & Ensoleiller (brightens) & 0.06 & 1,042 & Restreindre (restrict) & 2.87 & 1,100 \\
\hline Galeries (galeries) & 8.06 & 1,042 & Enseigne (sign) & 13.13 & 780 & Enceinte (pregnant) & 17.06 & 326 \\
\hline$M$ & 16.20 & 1,022 & & 9.37 & 995 & & 24.25 & 950 \\
\hline
\end{tabular}

Note-The English translation appears in parentheses. The target graphemes are underlined. Each word is associated to its word frequency (per million). The column further to the right indicates the bigram frequency between the letter preceding the grapheme and the grapheme (e.g., CLAVIER, PRAIRIE, PLAINTE). 